\title{
The happiest societies and the indigenous way of life
}

Renato Antunes Dos Santos, MD, PhD; Eduardo Chachamovich, MD, PhD; Marc Laporta, MD. McGill University, Department of Psychiatry, Montréal, Canada

Contact: renato.antunes@mail.mcgill.ca

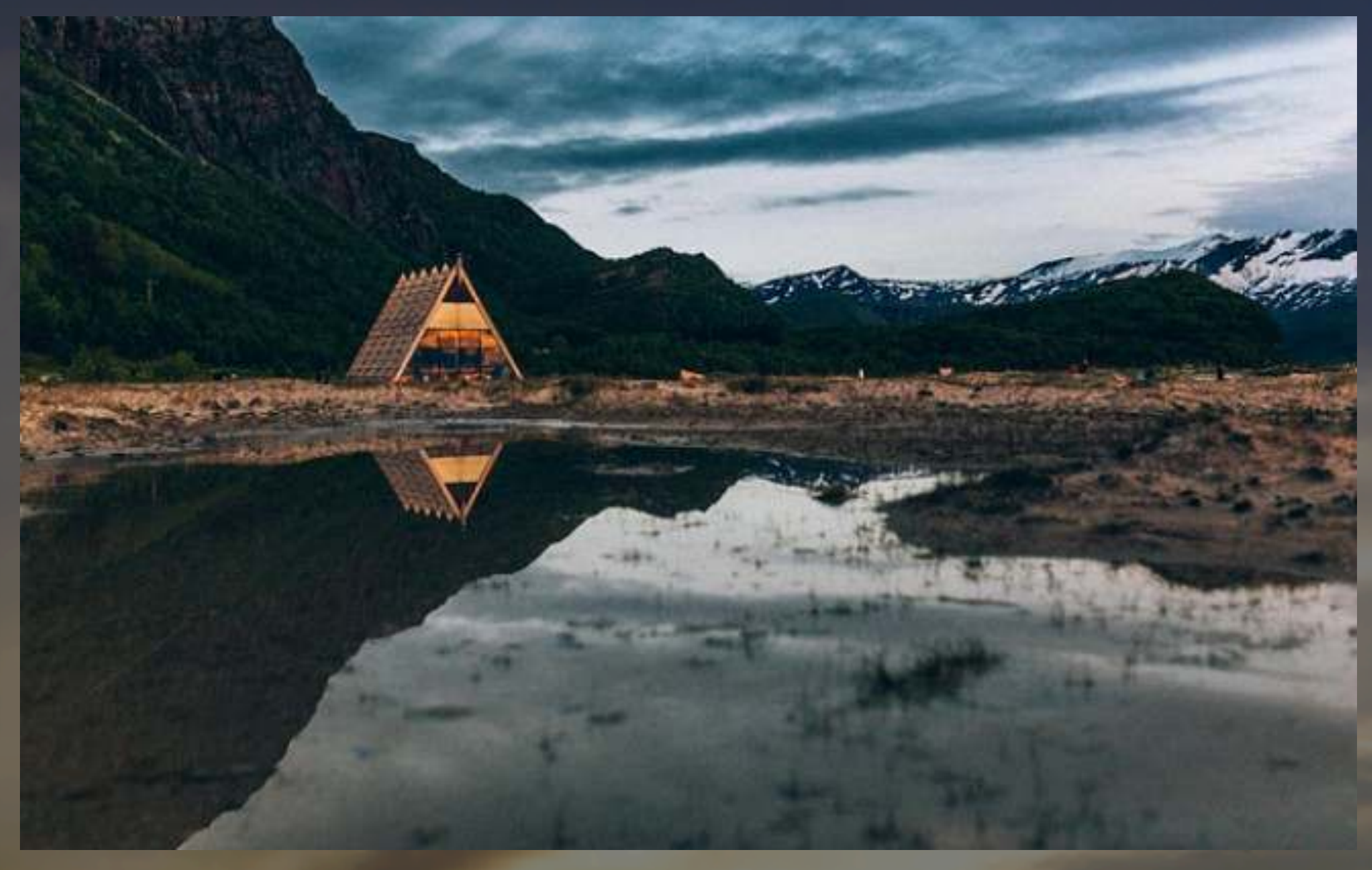

Objectives:

To analyze and discuss the relationship between the 'happiest societies' and the indigenous way of life Background:

According to the World Happiness Report by the United Nations, Scandinavians are continuously leading as the happiest societies in the world. Several studies have been undertaken in order to explain those good results. A closer look at the differences

between the Scandinavians compared to most western societies demonstrates values that might be considered approaching to indigenous values.

Often, the Scandinavian' way of life is presented as pursuing a classless society, where each different tasks in the society are truly considered important and necessary to contribute to the community's quality of life

(QoL). Education since the first years of school, emphasizes cooperation over competition.
Materials and Methods:

Literature review and critical analyses Results, Discussion and Conclusions: Similar to the Scandinavians, several Indigenous communities have been extolling for ages the ways of life leading to wellness, based on cultural and traditional values. It is not by chance that the happiest societies seem to gather the advantages of modern societies, preserving indigenous values. It seems that the original (or ab original) values are the major factors impacting positively wellbeing and quality of life not only for indigenous populations.

Nevertheless, the lack of empowerment and Agency might play a major role in the indigenous QoL nowadays ending up in the current tragic results to the mental health.

In the same way, several 'mainstream' western societies living by values farther from indigenous ones might be less happy.

It seems that both societies would gain adopting middle way strategies, learning from each other towards a better quality of life for all.
1. Czyzewski K. Colonialism as a broader social determinant of health. International Indigenous Policy Journal. 2011;2(1):5.

2. Helliwell J, Layard R, Sachs J. World happiness report. 2012.Avant GR, Knutsen KP UNDERSTANDING CULTURAL DIFFERENCES: Janteloven and Social Conformity in Norway. ETC: A Review of General Semantics. 1993;50(4):449-60.

3. Sandemose A. A fugitive crosses his tracks: AA Knopf; 1936.

4. Bainbridge, R. (2011). "Becoming empowered: a grounded theory study of Aboriginal women's agency." Australas Psychiatry 19 Suppl 1: S26-29.

Helliwell, J., et al. (2012). "World happiness report."

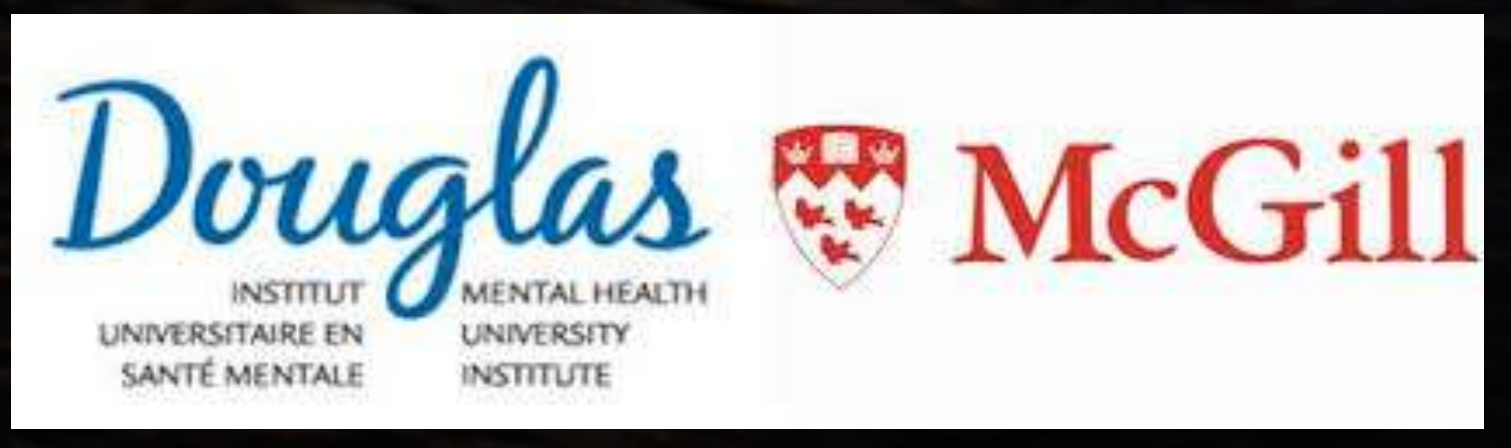

